\title{
The Impact of Behavioral-Social Disorders on Students' Education Drop-Off
}

\author{
Soosan Laei ${ }^{1}$, , Ali Abdi ${ }^{2}$, Mohamad Javad Karamaerouz $^{1}$, Nassim Shirkhani ${ }^{3}$ \\ ${ }^{1}$ Department of Educational Sciences, Kermanshah Branch, Islamic Azad University, Kermanshah, Iran \\ ${ }^{2}$ Department of Educational Sciences Payame noor University, Iran \\ ${ }^{3}$ Department of industries-industries, Science and Research Branch, Islamic Azad University,Arack, Iran \\ *Corresponding Author: s laei@yahoo.com
}

Copyright (C 2014 Horizon Research Publishing All rights reserved.

\begin{abstract}
Experts believe that adolescence is more challenging than childhood and is of critical importance. It is the period when the youth must be able to seek a philosophy for life and find an identity. Unfortunately nowadays most youths cannot learn developmental tasks successfully. The present descriptive study aims to identify pathological social-behavioral disorders and their impact on students' underachievement. The sample of the study consisted of 480 students aged between 12 and 17. Instrument of collecting data was a researcher-made likert-like questionnaire with 53 items, 15 positive and 38 negative. The face validity of the questionnaire was calculated with the Agreement coefficient formula. After calculating the consensus opinion of 20 experts, the questions whose coefficient of agreement was less than $70 \%$ were eliminated. Its reliability was also calculated as $85 \%$, using Cronbach alpha coefficient. Results showed that the rate of disorders in both male and female students will be equal if the overall level of disorders is considered separately. However, when a certain kind of disorder is considered, some differences are visible in both groups. Disorders include incompatibility, irritability, risk acceptance, indecisiveness, irresponsibility, feeling guilty, lack of trust in others, disrespect for authorities. The impact of these disorders on underachievement is more significant in girls than that of boys.
\end{abstract}

Keywords Social-Behavioral Disorders, Academic Achievement, Adolescence

\section{Introduction}

Adolescence is the time for rapid physical, sexual, psychological, cognitive and social changes. Since, adolescents ' relationship with their parents gets weaker in this period, peers may play a critical role on their mental development and pave the way for them to learn social skills, controlling behavior, share what they feel and discuss their problem [1]. This coincides with global changes as well as technological processes, the new forms of cultural challenge, which pave the way for increasing the so-called generation gap leading to conflicts between generations that some values have become counter values as a result of lack of a clear-cut definition, and some counter values have become values leading to some behavioral deviations in this age group. Ericsson suggests that adolescents, who know their "selves" in a short time, will face the risk of discovering other roles being provided in an inappropriate way and take many possibilities for granted [2].

Adolescents tend to be independent and objective to their parents and they question family values in order to prove their maturity and individuality and try to make and analyze their newly made values, although their chosen values are not the result of their rational decisions they've made logically. They choose their values for reasons related to their contradictions and motivations. These choices are sometimes unconscious. These are among major factors in emerging culture-value gaps between adolescents and their parents. This gap is sometimes so extended that opposes social values and norms and leads to behavioral-social disorders in this age group, so that it could make the community educational institutions make some efforts to control or remove this abnormally.

As the definition says, according to behavioral-social standard, abnormally or deviation is a behavior that not only causes destruction and braking social norms, but it also provokes negative feedback from others; hence, behaviors against social standards, criteria, and norms are considered abnormal and out of the ordinary [3].

In addition, these problems could have an immediate impact on our lives or leave indirect negative effects by increasing public service costs or developing anxiety among in individuals. A student, for example, who leaves school not only risks his future career, but also violate social health and public service costs [3], as a result socialization process is disturbed, emotional-social hurt and behavioral disorder and behavioral deviation, I. e. behavioral-social disorders, develops in adolescents. Behavioral-social disorders are common disabling disorders which collapse individuals and 
inhibit them from success, and also make families, school authorities and societies face a number of problems and high rate of social dilemmas. Pathology of these disorders in adolescence, as a harder time than childhood has captured considerable attention from experts and authorities. Pathology is the study of a set harms and behavioral disorders among adolescents that hurt adolescents' personality because of their development and deviation from norms and committing abnormal deeds in the community.

Many significant changes occur in this period; psychological are among the most significant changes in adolescence. A tendency toward peers in the process of socialization develops in adolescents in this period. In this life stage, adolescents need more emotional, economical, and personal independence and the most importantly they need to belong to a specific group called peers group and their acceptance [4]. In this period, adolescents must find a philosophy of life and their identities. These days unfortunately most adolescents cannot learn their developmental tasks successfully or they learn it with problems; therefore, there is a high rate of crime among adolescents.

Studies in the literature show that the statistics of behavioral harms such as violence, suicide, addiction to drugs, escape from home and school, illegal relationship with the opposite sex, aggression, assault and battery, and other behavioral social disorders is frequently repeated in this group of students. As an example, results from a study done by Gh. Kashkooli [5] with an epidemic investigation on elementary students' behavioral disorders in Boushehr indicated that the rate of childhood behavioral disorders in 1057 elementary students was $\% 17.43$ in urban schools, \%15.7 in rural school, \%14.16 female students and \%19.06 males students, that are hyper activity, aggression, anxiety, depression, social conflicts, anti social behaviors, lack of attention and distraction. In his study, Tavakoli Zadeh [6] suggested that there is a significant relationship between disorders and social-emotional situation, educational conditions, age, psychiatric disorders background in parents, etc. In their study, they investigated behavioral disorders among students in Kiev. The results showed that $19.8 \%$ of the students suffer from these disorders. Other studies also indicate that there is a high rate of behavioral disorder among adolescents and youth which should not be taken for granted. Thus, educational organization of Tehran explained the issue aiming to find answers to the questions:

What are the most common behavioral social disorders among students in Tehran? \& do these disorders have an impact on educational drop-off?

To answer these questions, the following research objectives were investigated:

1.1. Different kinds of behavioral social disorders among students of secondary school with respect to gender in Tehran

1.2. The impact of behavioral-social disorders on educational disorders in Tehran
1.3. The relationship between students' gender and their behavioral-social disorders in Tehran

\section{Materials and Methods}

\subsection{Methodology}

The present study is a descriptive non-experimental research aiming to investigate the rate of behavioral social disorders and their impact on educational drop-off in secondary and high school students. the students were selected randomly. The sample of the study using sample formula consisted of 480 secondary and high school students in Tehran in the school year of 2011-2012 who were selected using cluster sampling. First, the sample was divided to three groups: wealthy, average, and poor. Second, using random sampling 4 wealthy regions, 2 average regions, and 4 poor regions were selected. After that schools in all regions were identified and 4 schools consisting of two secondary and high schools were selected, 48 clusters were formed and 10 students were randomly selected from each cluster in each school. Finally, 480 was our sample size.

The instrument of the study was a 53-item research-made questioner with Likert scale range, 15 items were negative 38 items were positive. In order to show the validity of the questionnaire, 20 experts' viewpoints were collected and consistency coefficient was calculated using the following equation:

$$
C=\frac{\Sigma A}{\Sigma A+\Sigma B}
$$

In this formula, $\sum \mathrm{A}$ is the total number of yes answers and $\sum \mathrm{B}$ is all negative answers. Items with consistency coefficient lower than $70 \%$ were omitted.

In order to show the reliability of the instrument, it was distributed among 30 individual of the sample. Cronbach alpha was then calculated with reliability of $85 \%$.

\subsection{Statistical Analysis}

\subsubsection{What is the Most Common Behavioral-Social Disorder in Secondary and High School Students?}

In identifying the most common behavioral-social disorders the average scores for each disorder are taken into account. According to table (1), Disorders with higher mean than Liker range mean (2.5), which was used to measure and match the scores, were considered the most common disorders that the result of which is as follows:

As it can be seen, types of disorders in male and female secondary students were the same; however, their order was different, the rate of which was indicated based on the mean.

Table (2) as shown above, in addition to common disorders among males, there may be trends of low self confidence and high ignorance to authorities among females. 
Table 1. behavioral-social disorders in secondary

\begin{tabular}{cccc}
\hline $\begin{array}{c}\text { the most common } \\
\text { behavioral-social } \\
\text { disorders in boys }\end{array}$ & mean & $\begin{array}{c}\text { the most common } \\
\text { behavioral-social } \\
\text { disorders in girls }\end{array}$ & mean \\
\hline Conflict & 3.68 & Conflict & 3.71 \\
Irritability & 3.22 & Irritability & 3.23 \\
Risk taking & 3.10 & Risk taking & 3.29 \\
Irresponsibility & 3.03 & Lack of consistency & 3.10 \\
Lack of consistency & 2.95 & Feeling guilty & 3.08 \\
Distrust & 2.90 & Distrust & 3.03 \\
Ignorance to & 2.86 & Irresponsibility & 2.95 \\
authorities & 2.84 & Ignorance to authorities & 2.77 \\
Telling lies & 2.83 & Telling lies & 2.64 \\
Feeling guilty & & &
\end{tabular}

Table 2. behavioral-social disorders among high school students

\begin{tabular}{ccc}
\hline \multirow{2}{*}{ behavioral-social disorders } & \multicolumn{2}{c}{ mean } \\
in boys & in girls \\
\hline lack of consistency & 3.69 & 3.82 \\
Conflict & 3.54 & 3.71 \\
risk taking & 2.94 & 3.31 \\
Irritability & 2.92 & 3.27 \\
Isolation & 2.82 & 2.82 \\
Telling lies & 2.78 & 3.06 \\
Irresponsibility & 2.70 & 2.67 \\
feeling guilty & 2.61 & 2.82 \\
Ignorance to authorities & 2.56 & 3 \\
Low self-confidence & - & 2.74 \\
\end{tabular}

2.2.2. Do Behavioral-Social Disorders Influence Secondary Students' Educational Drop off?

To answer this question, the researcher compared educational scores of secondary school students with higher mean behavioral-social disorder with those of students with lower than mean disorders.

It should be noted that from this point onwards just a few examples are examined that the different genders and different courses of study and disorders are above average. Thus, the frequency will vary in different tables.

Table 3. Descriptive statistics for educational achievement scores

\begin{tabular}{cccc}
\hline Group & Mean & SD & $\begin{array}{c}\text { Mean of standard } \\
\text { error }\end{array}$ \\
\hline $\begin{array}{c}\text { Higher than mean } \\
\text { behavioral-social } \\
\text { disorder }\end{array}$ & 2.04733 & 17.8348 & 0.38691 \\
\hline $\begin{array}{c}\text { Lower than mean } \\
\text { behavioral-social } \\
\text { disorder }\end{array}$ & 3.30124 & 3.30124 & 1.65062 \\
\hline
\end{tabular}

In table (3) Students' total average as educational development scores in students with higher than mean disorders was 17.83 and in the group with lower than mean scores was 16.25. This discrepancy with $\mathrm{T}$ test of independent groups was investigated as follows:

Table 4. Test of independent groups

\begin{tabular}{ccccccc}
\hline & \multicolumn{3}{c}{$\begin{array}{c}\text { variance } \\
\text { consistency test }\end{array}$} & \multicolumn{3}{c}{ Level of confidence $=\mathbf{0 . 0 5}$} \\
\hline score & $\mathrm{f}$ & $\mathrm{Sig}$ & $\mathrm{t}$ & $\mathrm{df}$ & $\mathrm{Sig}$ \\
\hline $\begin{array}{c}\text { educational } \\
\text { development scores }\end{array}$ & 3.830 & 0.060 & 1.341 & 30 & 0.190 \\
\hline
\end{tabular}

In Table (4) the T test was 1.341 degree of freedom of 30 and level of 0.05 regarding significance level of $0.19>0.05$; therefore, null hypothesis is not rejected. That is by 9 percent the differences between means is not statistically significant and behavioral-social disorders do not influence educational achievement of secondary school students.

\subsubsection{Do Behavioral-Social Disorders Have an Impact on Educational Achievement in High School Students?}

To answer this question, shown in table 5 we compared mean scores of students with higher-than-mean students with those of students with lower than-mean disorders, using $\mathrm{T}$ test.

Table 5. Descriptive statistics for groups with Higher than mean difference and Lower than mean difference

\begin{tabular}{cccccc}
\hline Group & N & Mean & SD & $\begin{array}{c}\text { Mean of } \\
\text { standard } \\
\text { error }\end{array}$ \\
\hline Total & $\begin{array}{c}\text { Higher than } \\
\text { mean } \\
\text { difference }\end{array}$ & 153 & 16.2844 & 2.15156 & 0.17349 \\
average & $\begin{array}{c}\text { Lower than } \\
\text { mean } \\
\text { difference }\end{array}$ & 34 & 15.4591 & 1.90867 & 0.32733 \\
\hline
\end{tabular}

According to table (5), scores of educational achievement of high school students indicated based on this course's total mean. In students with higher than mean disorders was 16.28 and in students with lower than mean disorders was 15.64.

This difference in means was examined based on the consistency of variances with $\mathrm{T}$ test of independent groups:

Table 6. T test of independent groups

\begin{tabular}{cccccc}
\hline & \multicolumn{3}{c}{ variance consistency test } & \multicolumn{3}{c}{$\begin{array}{c}\text { Level of confidence }= \\
0.05\end{array}$} \\
\hline score & $\mathrm{f}$ & $\mathrm{Sig}$ & $\mathrm{t}$ & $\mathrm{df}$ & $\mathrm{Sig}$ \\
\hline $\begin{array}{c}\text { Educational } \\
\text { Achievemen }\end{array}$ & 0.656 & 0.419 & 2.063 & 185 & 0.041
\end{tabular}

According to test result of table (6), $\mathrm{t}$ was 2.063, that rejects null hypothesis with degree of freedom of 185 and significance level of 0.05 regarding significance level of $0.041<0.05$. That is, the difference between means is 
statically significant and by 95 percent student's educational achievement in high school is influenced by their behavioral-social disorders.

To investigate the differences between means by behavioral disorders in both male and female students, with respect to inconsistency of variances test of in contributed test $(\mathrm{sig}=0.023<0.05)$-U-Mann-Whitney non parametric test was used.

Table 7. Ranking means of secondary school students

\begin{tabular}{ccccc}
\hline & Gender & N & $\begin{array}{c}\text { Grade } \\
\text { mean }\end{array}$ & Total means \\
\hline & Female & 66 & 55.11 & 50.3637 \\
$\begin{array}{c}\text { Behavioral } \\
\text { disorders scores }\end{array}$ & Male & 40 & 50.84 & 50.2033 \\
& total & 106 & & \\
\hline
\end{tabular}

According to the table (7), In U-Mann-Whitney test, scores of behavioral disorders in 66 female students and 40 male students were ranked. Females' mean was 55.11 and males' mean was 50.84 .

Table 8. U-Mann-Whithney test for investigate the differences between means by behavioral disorders in both male and female students in secondary school

\begin{tabular}{cc}
\hline & Behavioral disorders \\
\hline U-Mann - Whitney & 1213.500 \\
Z scores & -0.644 \\
Sig & 0.488 \\
\hline
\end{tabular}

According to table (8), in this test, ranks' mean in both groups were compared, and $\mathrm{U}=1213.5$ and $\mathrm{Z}=-0.694$ which was smaller than indicator size of $Z$ at alpha level of (1.96) 0.05 ; therefore, the null hypothesis is not rejected. That is the difference between scores of behavioral disorders was not statistically significant, and there was no significant difference in the rate of these disorders between secondary school boys and girls.

However, in behavioral disorders in high school students significance level was $0.306>0.05$ and the frequency was $\mathrm{f}=1.054$. Thus, in order to investigate the mean difference of disorders among both male and female groups parametric t-test was employed:

Table 9. T test for mean of disorders in high school

\begin{tabular}{ccccc}
\hline Gender & N & Mean & SD & $\begin{array}{c}\text { Mean of standard } \\
\text { error }\end{array}$ \\
Female & 142 & 54.4268 & 7.63310 & 0.64056 \\
Male & 125 & 53.4593 & 7.31955 & 0.65472 \\
\hline
\end{tabular}

According to the table (9): Mean of scores for behavioral-social disorders in 142 high school girls, was 54.423 with $\mathrm{SD}=7.63310$ and in 125 boys was 53.4593 with $\mathrm{SD}=7.31995$.

As shown in table (10), $\mathrm{t}=1.054$, with respect to sig $=$
$0.293>0.05$ and degree of freedom of 265 indicates the rejection of null hypothesis and there is a statistically significant difference between means of disorders among high school boys and girls. In other words in high school boys there exist much more behavioral disorders than in girls.

Table 10. Statistics groups to investigate the level of disorders in high school students

\begin{tabular}{cccc}
\hline & \multicolumn{4}{c}{ Level of confidence $=\mathbf{0 . 0 5}$} \\
\hline score & $\mathrm{t}$ & $\mathrm{df}$ & $\mathrm{Sig}$ \\
\hline $\begin{array}{c}\text { Assuming } \\
\text { consistency of } \\
\text { variances }\end{array}$ & 1.05 & 265 & 0.293 \\
\hline
\end{tabular}

\section{Conclusion}

Any comments and suggestions are welcomed so that we can constantly improve this template to satisfy all authors' research needs

\subsection{Types of Behavioral Rate in Secondary School}

Investigation on rate and types of behavioral disorders in secondary school students show that is 83.7 percent of the sample disorders stand more at the first quarter and lower than mean of the first half which shows a low level of disorders in secondary school students, also in only 1.1 percent of students this level is close to the mean.

The most common disorders in secondary school students are: risk taking, irresponsible, inconsistency, distrust, ignorance to authorities, telling lies, and feeling guilty. As such, this type of disorders in secondary school boys and girls was the same; however, this does not mean that there are no other disorders in them, but there are other kinds of disorders reported by students with limited ranges, but most students denied to reply questions regarding risky behaviors like abusing alcohol, drugs, robbery and contention.

A comparison of responses frequencies in personal disorders like conflict, distrust, irritability, feeling guilty, etc., with that of responses to behavioral disorders like robbery, abusing alcohol and drugs, befriending with opposite sex, etc. showed the students had orientations in getting responses to disorders, which didn't mean rejection from society for them, if proved. In other words, one can say that students deny some of their behavioral aspects in order not to be rejected by society.

Other studies in this literature prove the existence of disorders in this period. In a study, in elementary students in Yasouj by Qader-Zade [7], for example, it was suggested that 11-13-year-old students experience more behavioral disorders than other levels. Another study on 11-14-year-old students showed that there was no significant difference in behavioral disorders between boy and girls. Behavioral patterns, however, appeared to be different in boys and girls and a total of 16.5 percent of the subjects had behavioral 
emotional problems. Comparison of scores of male and female students indicated that there was no statistically significant difference between the two groups. According to Mirza'ee [8], the rate of behavioral disorders was 5.53 in girls. Also, Yousefi [9] in a study on 2670 secondary school subjects reported levels of disorder available according to different regions wherein the research was done and the type of the disorders.

As seen above other studies in previous years and in different regions of Iran, all show a level of disorders in students' behaviors with different rates. This difference may result from differences in geographical regions and different times of conducting the research.

\subsection{Types of Behavioral Rate in High School}

In investigating the rate and types of high school students' behavioral disorders, it was shown that in 88 percent of high school student there was a level of behavioral social disorders, that was lower than mean and only in 7.9 percent of the sample this rate was close to the mean. Distribution of scores from maximum to minimum shows the different levels of discords in high school time.

The most common disorders among high school students are inconsistency, conflict, risk taking, irritability, isolation, ignorance to rules (laws) and regulations, feeling guilty, telling lies, irresponsibility, ignorance to authorities (principals and their assistance, parents, etc.), and low self confidence. Generally, high school students have other disorders in addition to those mentioned for secondary school students there is an increase in mean in other disorders such as depression, anxiety, and contention, as well.

Other studies in the literature also show behavioral disorders among high school students. As an example, Rajabi [10] studied the rate of behavioral disorders in Qazvin high school students the results of which showed that the rate of behavioral disorders in high school students is 4 percent more than its national figure. However, this research found no significant relationship between educational grades and the rate of disorders.

The results of other research showed that the rate of depression, isolation, compulsiveness, and affectivity in girls was significantly more than boys, but the rate o aggression and restiveness in high school boys was more than girls. As seen in previous studies in this literature, existence of behavioral disorders in a population of students was investigated and admitted which might be the result of time gaps and environments of doing studies.

\subsection{Comparison of Secondary and High School}

A comparison of secondary and high school boys and girls showed that according to the results the rate of behavioral social disorders in both male and female secondary school students was the same and gender seems to have no effect on the rate of this disorders. This was suggested in studies by
Yousefi [9]. However this difference was statistically significant in both male and female high school students, but its rate was not the same for both groups. In other words, gender has no impact on disorders in secondary school time, whilst this difference was significant in high school time and girls' ignorance to authorities (principals and their assistants, parents, etc.) and low elf confidence disorders have a high mean than those of boys.

In study, Molla Hamzezadeh [11] found that behavioral problems in students had a relationship to gender and educational conditions and the rate of depression in female students, and aggressiveness in males had a higher rate. In another study, Rajabi [10] also investigated the rate of behavioral disorders in high school students the result of which showed that the rate of behavioral disorders in girls was significantly more than in boys whereas, Iranpour [12] observed in their study that there was no significant difference regarding behavioral disorders in males and females.

Results from studies in the literature indicated that whenever a specific type of disorder is investigated, the difference between rate of disorders in males and females is apparent, but different types of disorders come together to show a total level of disorder, the total mean of scores for each type of the disorders in male and female groups covers the differences resulted from gender, and finally it shows an equal rate of scores in both groups.

\subsection{Behavioral-social and Educational Achievement}

Investigation of the impact of behavioral-social disorders on student's educational achievement: according to the results, with 95 percent of confidence, behavioral-social disorders in high school students can have an impact on their educational achievement which is followed by an educational drop-off, whereas it is not apparent in secondary school time.

It should be mentioned here that the level of these disorders in secondary school students, as mentioned before was lower than the mean and one of the reasons for lack of the influence on educational achievement could be the limits for the preset level of disorders. Also it is possible to increase side involvement in students which can be followed by educational drop-off, as seen in high school time. In a study, Tavakolizadeh [6] indicated that rate of behavioral disorders had a meaningful relationship to educational conditions.

Safaee [13] studied and compared some behavioral disorders in elementary students of Golpayegan, the results of which showed that tee is a contradictory and converse relationship between behavioral disorders and educational performance. Studies by Safaee [13], Aslani [14], and other studies also show a meaningful relationship between the rate of disorders and educational achievement

\subsection{Academic Achievement of Girls and Boys}

According to statistic results from the importance rate of 
disorders in educational achievement in students and it can be observed that we should indicate whether the impact of disorders on educational behavior is influenced by gender or not. Results indicate the impact of disorders on educational achievement in girls. In other words, disorders increase the possibility of educational drop-off more in girls than in boys. There are no studies available to show that the impact of the rate of behavioral social disorders on educational drop-off in girls is more significant than in boys. Hence, we can compare these results with those from other studies. In other words to ensure the results this problem should be investigated indirectly in the future studies.

\section{REFERENCES}

[1] P. H. Massen, and others, the child's personality development, Translator: Mahshid Yasayy, Tehran, Center, 1999.

[2] H. Ganji, developmental psychology, Tehran, Savalan, 2004.

[3] H. Ganji, R. Hassanzadeh, Social Psychology of Education, Tehran, Sokhan, 1999.

[4] A. Akbari. the problems of youth, Tehran, Savalan, 2002.

[5] F. Kashkouli, epidemiological and behavioral disorders in a primary school in Bushehr. Proceedings of the Fifth National Conference on Child and Adolescent Mental Health, Zanjan University of Medical Sciences, 2003.

[6] M. Tavakolizadeh, Me. Bolhari, and others. Epidemic of
behavioral-Social disorders and Attention Deficit elementary students of gonabad city, 2003.

[7] B. Ghaderzadeh, Evaluation of behavioral disorders in primary school students aged 6 to 13 Yasouj, Proceedings of the Fifth Seminar on child and adolescent mental health, Yasouj medical science, 2003.

[8] M. Mirzaei, Prevalence of behavior disorders from the perspective of parents of children 6 to 12 years, undergraduate research and education organization in Qazvin province, 2001.

[9] A. Yosephi, Prevalence of defiance disorder and conduct disorder in schoolchildren coping tips, Kurdistan Ministry of Education, Research Council, 1999.

[10] M. Rajabi, the prevalence of behavioral disorders in high school students in Qazvin, Qazvin undergraduate research of education organization, 2002.

[11] V. Mollahamzeh examines the role of family dysfunction in behavioral problems of students and high school guidance, Ardebil Province, Ministry of Education, Research Council, 2001.

[12] Ch. Iranpour, A. Mahyar, Comparative study of behavioral disorders among Children of poor families and densely populated. Fourth seminar Mental Health and behavioral disorders in children and adolescents. Zanjan University of Medical Sciences, 2000.

[13] E. Safaei, Comparison of behavioral problems in Fatherless children and normalIn schools Golpaygan city, Allameh Tabatabai University, 2002.

[14] S. Aslani, Social Factors girls running away from home, Esfahan University, 2002. 